\title{
Government policies for the prevention of violence in schools in Brazil and the citizenship education
}

\author{
Joyce Mary Adam ${ }^{1 \mathrm{a}}$ and Claudia Sorgon Scotuzzi ${ }^{2}$ \\ ${ }^{1}$ Universidade Estadual Paulista-Unesp, Rio Claro-SP, 13506-900, Brazil \\ ${ }^{2}$ Diretoria de Ensino de Limeira-SP, Brazil
}

\begin{abstract}
The main objective of this work is to discuss some of the policies for the prevention of school violence in Brazil, specifically in the States of São Paulo and Minas Gerais, seeking to reflect on the role of citizenship education in these States. One of the core issues is whether these policies are aimed at developing the values of citizenship. As a conclusion, we pointed out that the feelings of social insecurity are reflected in the relationships inside the big schools generating an intolerance to behaviour considered as antisocial, which, in general, is directed mainly at the poor youths from outlying neighbourhoods. After analysing the documents, we consider that the state of São Paulo as well as Minas Gerais have sought partnerships with judiciary organs to restore the balance broken in the school environment as a result of conflict situations. This attitude does not prioritize a pedagogical education through the citizenship.
\end{abstract}

Keywords: Educational policies; school violence; citizenship; prevention of school violence

\section{Violence and violence in schools: Notes on the social issue}

The relations in our schools are a result from the social violence through a diffuse violence that is present in our everyday social relations, not only in the relations between students, but also between them and other school professionals such as teachers, administrators and employees. Such violence takes place before a crime, and is not classified as a crime in our penal code, because it is legitimized by the collective consciousness, establishing itself as a social norm, although controversial [6]. The phenomenon of diffuse violence permeates our social relations in the XXI century, leading to an unexpected result in terms of civilizational advancement and citizenship values. We would like to point out, however, that the conflicts generated in the daily interactions in schools mask the real motives and sources of such conflicts, which would be primarily

\footnotetext{
${ }^{a}$ Corresponding author: joyce@rc.unesp.br
} 
related to a difficulty to understand the reality and the actual living conditions of our students, and the difficulty by the school system to define the borderlines between violence, crime and indiscipline.

We point out the significant increase in policies and legislation designed to rule behaviors, and punitive measures targeting students that focus on coercion and repression rather than learning the values of a civic education. Another aspect to point out is that teachers and other education professionals do not feel they are appropriately trained to handle the problems of violence in schools, since many do not consider they are capable of this, and they think that their basic training as teachers did not provide them the tools required for such work. For Royer, the basic and continuous training of teachers about violence in schools should be based on the belief that access to education is a right of all young people and also on the fundamental belief in the fact that it is better to educate than to punish. Therefore it is necessary to emphasize the development of tools that will promote positive changes, along with the evaluation of new ideas and new practices that can increase teachers' self-confidence.

This issue, however, requires a discussion about the meaning of what Bailleau and Gorgeon [2] pointed out, which is the idea of inclusion, i.e. behaving according to the rules from established cultural references. Such cultural references refer both to the culture of survival of institutions such as the "culture de survie", survival culture of poor young people as a result of the economic, political and social setting, as behaviors of resistance and identity affirmation.

After taking this into account, one can discuss proposals that will focus on the interactions among the different players in the school system, regardless of the context in which these relationships are produced. The focus on conflict mediation, or an uncritical view of the proposed "education for peace" that ignores this "a priori" in the relationships that are established, rather than bringing positive results in terms of integration and participation, can conceal the source of conflicts and only strengthen the dominant logic.

In the last few decades, different proposals for conflict mediation have been introduced for the discussion of both social and school-basic conflicts.

Regarding the conflict mediation proposals that have been put in place in France with respect to population and public services, Bailleau and Gorgeon [2, p. 26] introduce a critical view pointing to the discussion of two central issues which would be, firstly the lack of responsibility by institutions and professionals regarding the consideration of new social realities, thereby reducing such discussion to mediation techniques; secondly the risk of being a constant intermediary between users, citizens and public institutions. Therefore, in school institutions, also, conflict mediation proposals must be thought of in terms of how to promote the discussion about different cultures and power games among the different groups, and how much the single logic of the institution can be imposed as far as it is an entity that is independent of the ones working in such entity.

Among the different proposals of conflict mediation in schools, the use of restorative justice concepts has appeared frequently. The proposals involving restorative justice concepts, while focusing on more positive and less punitive aspects, have a social control component that is associated to the legal issue. As noted by MacCluskey [4], the language used by the legal system, such as 'offender and victim', derives from the criminal justice system and from its related psychological perspectives, which makes them inappropriate for use in the school organization. The terms often used in the restorative justice, such as transgressor or offender, and wronged or victimized, have their meaning associated to misdemeanors or crimes; and transferring such terms to the school system can lead to misleading actions and criminalize actions that would be better defined as indiscipline or incivility. The example given by McCluskey et all [4] draws attention to this: 
In Scotland, for example, the most common reason for school exclusion is 'general and persistent disobedience'. Pupils are, in fact, rarely excluded for acts of violence and the relationship between pupils who disrupt and those disrupted is complex [3, 4]. The borrowing of terms such as 'victim' and 'perpetrator' from criminal justice may then reinforce a discourse that demonizes and criminalizes young people in general. As argued in $[3,4]$, 'it often appears that the best that young people can hope for ... is to be labeled as victims unable to cope with the pressures of life, rather than as villains who are destroying it'.

Another aspect pointed out by McCluskey [4] is that the restorative justice, by focusing on the fact itself, fails to discuss how the offender has become an offender, thereby ignoring issues such as power, class and gender.

In an article in 2002, Gonçalves and Sposito [5] point out that in Brazil, for the last twenty years, public policies designed to reduce violence in schools have their main source at the state and municipal level (p.102). One can see that after 10 years, the initiatives remain under the main responsibility of states and municipalities, but with a more significant number of practical proposals to be implemented. These authors emphasize the attention of the Ministry of Justice on the issue of violence among young people, more specifically from the $90 \mathrm{~s}$, with the incidence of different episodes of violence carried out by young people. A few years later, in the late 90 's and early 2000, more eyes have looked more closely into the issue of violence in schools.

In this line of discussion, there is a growing proposition for policies that can prevent violence in schools by building partnerships between agencies related to the legal system including the Public Ministry and others, and non-governmental organizations. One of such initiatives proposed by the federal government, inspired by the worldwide movement, is the Peace in Schools project, developed in 14 states, proposing "training" teachers to face the conflicts of violence in schools. Proposals for "education for peace" have widespread strength and many state governments in Brazil have developed policies based on this principle, but one can see that agencies associated with the police repression and the legal system are predominant in these proposals, as can be seen in what is shown below.

\section{School violence prevention policies in São Paulo and Minas Gerais: prevention, punishment and citizenship}

Based on our research above, we have just finish and quickly mapped some proposals that are under development in the state of São Paulo.

Among the policies that have been developed with the purpose of preventing violence in schools, we highlight the following:

a) Project Prevention is Also Taught and Present Community. Developed by the Foundation for the Development of Education, through the DPE - Office of Special Projects in São Paulo public schools. According to the document, this initiative had as its purpose to promote a healthy citizenship while reducing the vulnerability of the school community to teenage pregnancy and drug abuse and STD/AIDS (sexually transmitted disease/acquired immunodeficiency syndrome). The project continues up to this date and is based on a continuing education that proposes to provide conditions for the development of self-esteem of students and a sense of responsibility about the need for individual and collective health. Additionally, it seeks to empower educators and provide tools for São Paulo public schools to promote conflict mediation in situations of violence in schools, in order to provide good coexistence and integration between schools and the community. In the last guide produced for schools, the topics that were discussed were: conscious consumption; adolescence and sexuality; gender and prejudice; bullying and other types of violence; alcohol, tobacco and other drugs; preventing STD, HIV and AIDS. 
This proposal introduces the significant principles and actions to be worked in schools, ranging from the issue of health, which is very present in government proposals for schools, such as preventing pregnancy and sexually transmitted diseases, and also the issue of prejudice of race, color and gender. All these issues are important when discussing citizenship; however, on the issue of violence in schools, it continues to focus on students as the source of conflicts in schools. Bullying, cyberbullying, etc. are the main focus of the text about violence in schools and it never discusses the school while a complex organization and also a source of conflict by imposing its rules. As previously mentioned in Bailleau and Gorgeon [2], violence in schools must take into account how much schools are approached in terms of how to promote a discussion about different cultures and power games among the different groups and how much a single logic is forced by the institution as an entity that is independent from the ones that work in it.

b) Project Justice and Education: a partnership for citizenship. Developed after a partnership between the Office of Education and the Justice Court of the State of São Paulo, with participation of judges from the Courts for Children's and Youth, the Project Justice and Education: a partnership for citizenship was implemented in state schools of Primary and Secondary Education. The project is designed to develop the skills to solve conflicts in schools in a preventive way, thereby preventing conflicts from being sent to the legal system, and those that are not related to the school community experience, at the Forum in Restorative Circles, thereby strengthening the community networks to act in a coordinated way [1].

One can note the strong presence of agencies associated with to the legal system in this project, therefore supporting what we have stated before: the legal character that permeates the system, despite proposals for a collective construction of the rules, empowerment of the groups involved, etc.

c) School Protection System. It is the most recent Public Policy program to prevent and/or minimize violence in schools, created by the Office of Education of the State of São Paulo, in partnership with the Office of Public Safety and the Foundation for the Development of Education (FDE). SEE started from the supposition that multiple sociocultural variables can, at the same time, impact a school learning effort and stimulate transformative actions and, as a result, in 2009 it made available, the "Manual for School Protection Promotion of Citizenship", and "General Policies for School Behavior" for all schools in the State education system.

In a previous publication [1] we have pointed out that the Manual for School Protection and Promotion of Citizenship, by conceptually defining what is a crime, misdemeanor and infraction, point out that the latter, "includes misdemeanors and crimes committed by a person under 18" [9]. However, when describing misdemeanors that take place in schools, the text uses the term crime, repeatedly and also provides a list of "most common crimes in schools" (p.15), including damages, graffiti and threats, and firearms, drug trafficking and rape. All are described are equally serious. It also uses legal terms to qualify students as "apenados" for teenagers that are in conflict with the law and who are doing socioeducational actions and simplistic solutions like the suggestion, when describing bullying in schools, that only referrals to therapeutic treatment and warning by the Guardian Council to offending students as effective to "reduce" the repetition of such undesirable behavior. Another relevant aspect, we showed like to point out in the material, with regard to the treatment given to students who commit the so-called "misdemeanors" is an established differentiation in similar actions for students and servants. Let's take, as an example, a person under the influence of drugs or alcohol in schools. When it comes to a servant, after the immediate actions by the school principal, such as determining the return of such servant to his/her home, the material provides a list of guidelines that can be followed in order to avoid future conflicts and help to adapt such servant to his/her workplace. When 
talking about students, the material guideline, with regard to drugs, is that "regardless of a student age, the Military Police (190) should be called so that the appropriate measures are taken $[9$, p.33]".

One can see, in the documents that were reviewed, there is a strong punitive recommendation for students, while there are no references to the rules and type of organization present in schools as an important element to be considered when discussing conflicts that take place in the school environment. One can notice that citizenship is mentioned at different times, but in actual terms, the proposed actions, the principles of citizenship are significantly misrepresented and the legal and police actions are overrated valued.

The state of Minas Gerais has been developing government proposals with the support of institutions associated to the legal system and non-governmental organizations, aligned with the Education for Peace and, in 2011, it created the "Intersector Group for Confronting the Violence Generating Conditions in the State Public Schools System". This group reviews the different types of violence in schools in its space and its surroundings. In Minas Gerais, the following projects have been proposed, which are projects with actions in schools or actions focused on youth violence in general:

a) Active Community Living School. This project seeks to strengthen schools that are located in areas with a social vulnerability and which have significant levels of violence, according to a summarized report from the Intersector Group. Currently 440 thousand students are engaged in 501 schools, located in 103 municipalities in different regions of the state.

b) Forpaz- Peacebuilding Forum. FORPAZ is a joint initiative by the Office of State of Education in Minas Gerais- SEE- and the Public Security of the state of Minas Gerais in a partnership with the committee of representation of the Technical Security Forum in Schools for a culture of peace of the Legislative Assembly of the state of Minas Gerais. FORPAZ focus are: conflict mediation: awareness, training and implementation of Project MESC - Conflict Mediation in the School Environment (coordinated by the Public Security of Belo Horizonte); implementation of Restorative Justice programs in schools in the state school system; exchange and dissemination of successful experiences of the state system; campaigns to mobilize the school community; training to teachers on issues related to promoting peace at schools.

The positives elements of FORPAZ proposal are related to actions developed with school communities including: community mobilization for a joint action with respect to violence in schools, exchange of good experiences and training in conflict mediation by the school community. We would like to point out, however, that there is the presence of the public security, which gives a judicial character to the actions that are developed. By questioning such a situation, a member of the office of Education pointed out that by participating in such activities, the judicial system highlights that it is up to schools to address conflicts in schools rather than the legal system, because the legal system should be called in cases that are considered to be a crime.

Other projects that are not directly focused on the school system, but are related to the prevention of youth violence in general and which are in the proposed safety system are the following:

a) Projects by the state of Office of Social Security: conflict mediation project; homicide control project- Staying Alive.

b) Projects by the Civil Police: Mediate Project; drugs project: knowledge for informed choices; social networks project; school graffiti project.

c) The Military Police Projects: PROERD- Educational Program of Resistance to Drugs; Project Youth Building Citizenship; School Patrol project.

d) The Fire Department Projects: Young Firefighter Project 
e) Projects by the State Office of Health: Center for Violence Prevention, Culture for Peace and Health Promotion; Center for Children and teenagers.

f) State Office for Social Development: Youth Savings

The listed projects proposed and developed courses and written materials, such as brochures, that were developed for professionals working in public schools to prevent violence in schools and "train" such professionals to mediate conflicts in schools. In order to analyze the scope, limits and mistakes of such propositions, we propose an analysis of such policies.

\section{Conclusions}

After examining the documents, we believe that both the state of São Paulo and the state of Minas Gerais, through their State Office of Education, have sought, in partnership with legal Agencies, the possibilities of restoring a balance that has been broken in the school system as a result of conflict situations.

However, the proposals by these agencies, relating to the culture of peace and restorative actions in school, do nothing more than give a new look to issues that are inherently pedagogical. The teacher role has an eminently mediating character. Restorative policies have been developed in schools, in activities such as conversation circles, debates and others. It seems, however, that schools have lost their focus, therefore becoming pedagogically unable to solve the problems related to the coexistence and social relations in its facilities, therefore allowing the interference by Security institutions in schools by adding a legal characteristic to these relationships.

Basically, all initiatives by the state of São Paulo, whether with the Present Community Project, Project Justice and Education: a partnership for citizenship or the Mediating Teacher, bring the Legal component to the school environment. Although having small gains in their relations, as seen in statements given by School Principals, the Mediating Teacher is a very lonely character in a school environment where the focus on the source of conflicts in school is on the student, where no one discusses the school as an a complex organization and also a source of conflicts because of its excluding characteristic.

The state of Minas Gerais introduces a positive component in its political proposals, namely the involvement of the whole community to learn and practice school mediation. However, most of its policies, also involves legal agencies, such as the Public Defense, Civil and Military Police, Fire Department, among others.

We conclude by saying that, although in today's society the partnerships are considered to be of fundamental importance, when we think to prevent and/or minimize episodes of violence in schools, the school work must focus on and reaffirm actions in which the key players are the education players themselves. A work that relies on external partners, but is independent from them, because it should be thought of and implemented primarily by people from all school segments, including, of course, the families and the local community.

\section{References}

1. Adam, J.M., Scotuzzi, C.A.S., School protection system: Protecting who, from whom? Procedia: Social and Behavioral Sciences, 55, 429-434, (2012).

2. Bailleau, F., Gorgeon,C., Vers un nouvel ordre social? Une autre lecture des questions d'ins'curité et de delinquance. Paris: Editions DIV, (1999). 
3. Mccluskey, G .et al., 'I was dead restorative today': From restorative justice to restorative approaches in school. Cambridge Journal of Education, 38, (2),199-216, (2001).

4. Mccluskey, $\mathrm{G}$.et al., Can restorative practices in schools make a difference? Educational Review, 60(4), 405-417, (2008).

5. Gonçalves, L.A. O.; Sposito, M.P., Iniciativas públicas de redução da violência escolar no Brasil. Cadernos de Pesquisa, 115,101-138, (2002).

6. Tavares dos Santos. J. T., Violências e dilemas do controle Social nas sociedades da "modernidade tardia". São Paulo em Perspectiva, 18(1), 3-12, (2004).

7. FDE- Diretoria de Projetos Especiais, Projetos comunidade presente e prevenção também se ensina: Sugestões de atividades preventivas para HTPC e sala de aula. Fundação para o Desenvolvimento da Educação. -São Paulo: Fundação para o Desenvolvimento da Educação, (2012).

8. FDE/CECIP., Justiça e educação em Heliópolis e Guarulhos: parceria para a cidadania/Madza Ednir, organizadora. São Paulo: CECIP, (2007).

9. São Paulo (a)., Secretaria de Estado da Educação. Manual de Proteção Escolar e Promoção da Cidadania. São Paulo: FDE, (2009).

10. São Paulo., Secretaria de Estado da Educação. Normas Gerais de Conduta Escolar. São Paulo: FDE, (2009).

11. Minas Gerais., Grupo Intersetorial de Enfrentamento das Condições Geradoras de Violência nas Escolas da Rede Pública Estadual. 